\title{
Electric Power Quality Monitoring Results in Different Facilities
}

\author{
Renato Alves ${ }^{1}$, Pedro Neves ${ }^{1}$,D. Gonçalves ${ }^{1}, J_{\text {. G. Pinto }}{ }^{1}$, José Batista ${ }^{2}$, João L. Afonso ${ }^{1}$ \\ ${ }^{1}$ DEI, University of Minho, Portugal. \\ ${ }^{2}$ Polytechnic Institute of Bragança, Portugal. \\ E-mail: \{ralves| pneves| dgoncalves|gpinto|jla\}@dei.uminho.pt,jbatista@ipb.pt
}

\begin{abstract}
This paper presents results of electric power quality monitoring studies performed in different industries and in universities. The monitoring was made with an Electric Power Quality Monitor developed at the University of Minho. The studies were performed in different installations: textile industries, a pharmaceutical industry, a hospital and two universities. Therefore, the results showed in this paper were obtained in different electrical installations. It is important to emphasize that, the results here presented are not intended to establish profiles for each type of electrical installation. The aim is rather to show several electric power problems that occur in these types of facilities, and also to present the functionalities of the Electric Power Quality Monitor developed at the University of Minho, working out of laboratory, in real electrical installations.
\end{abstract}

\section{INTRODUCTION}

Due to the great development of electronics equipment in recent decades, there has been a proliferation of non linear loads in electrical installations. Therefore, more problems arise in electrical installations which may cause large economic losses. Some electronic equipment, beyond consuming distorted currents, also require rigorous parameters of electric energy, meaning that a small disturbance may be enough for their malfunctioning, or even, in the most extreme cases, to cause their damage. For these reasons, the Electric Power Quality each time gains more importance in the project and maintenance of the electric installations. The monitoring of Electric Power Quality is an important tool to detect problems that may be affecting the equipment or the electrical installation. An effective Power Quality Monitoring may also prevent future problems that might cause damage of equipments or premature aging of the installation components like transformers, circuit breakers even the electrical wiring can be affected.

During many years, the Electric Power Quality basically was limited to interruptions in the energy supply. Currently, many other factors influence the quality of energy, since the number of sensitive loads is increasing at the same time that the non linear current consumption augments the voltage waveform distortion. Among the Electric Power Quality problems, the following are distinguished: sags, swells, transients, harmonics, high-frequency noise, notches, flicker, unbalances and frequency variations.

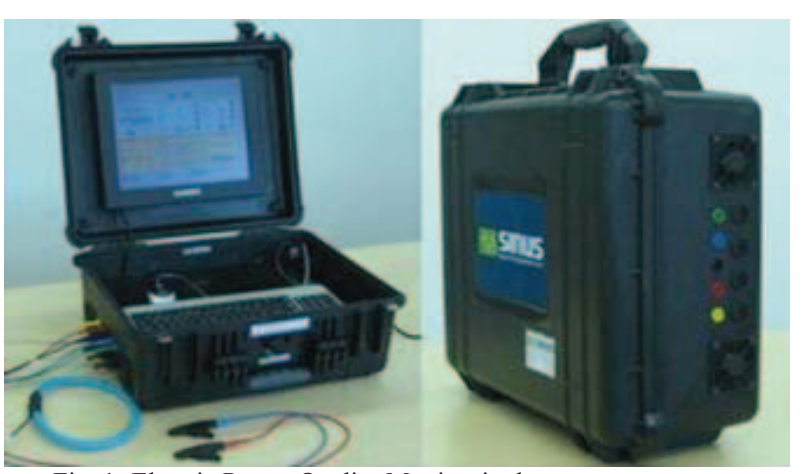

Fig. 1- Electric Power Quality Monitor in the transport case.

This paper presents the results of Electric Power Quality monitoring jobs made in multiple companies of different kinds, like textile industries, warehouses, universities and a hospital.

Fig.1 shows a picture of the Power Quality Monitor prototype developed at Energy and Power Electronics laboratory of the University of Minho. The prototype is assembled in a strong plastic case with easy to connect plugs for power and sensors and a built-in 14 inch TFT monitor. To allow the Electric Power Quality Monitor to record the consequences of the failure and also the consequences of the return of the electric power, the prototype was equipped with a backup battery, so, it continues working in the occurrence of power outages. Actually the backup autonomy is approximately an hour and a half, but, this time may be easily increased if greater autonomy is desired.

The Electric Power Monitor prototype contains multiple software applications that allow the execution of multiple tasks with the same equipment. So, the same equipment is used to observe, monitor, or record electric power characteristics and events.

\section{DESCRIPTION OF THE ELECTRIC POWER QUALITY MONITOR}

The Electric Power Quality Monitor presented in Fig. 1 is an equipment that has been developed in the Laboratory of Power Electronics of the Industrial Electronics Department of the University of Minho. This equipment has the ability to analyze the power quality of an electrical installation, and also to record and classify some of the problems. In terms of 
hardware the Monitor consists on four voltage sensors, four current sensors, one signal conditioning board, one data acquisition card and one Personal Computer [1] [2] [3].

The software of the Electric Power Quality Monitor is constituted by several applications and is based in LabView. The developed applications allow the equipment to function like a digital oscilloscope, analyze harmonic contents, detect and record voltage distortions (sags, swells, interruptions, wave shapes), measure energy, power, voltage and current unbalance, power factor, record and watch strip charts and generate reports [1] [4] [5] [6].

In Fig. 2, it can be seen the Electric Power Quality Monitor installed in an electrical switchboard in a university. The door of the electric switchboard had to be left opened, so that the sensors could reach the points to be measured, but it occurred in a technical room, where only authorized personal can enter. The Monitor, in the transport case, could be left unattended during one month, until the monitoring was over.

Fig. 3 shows an interface screen of the application named "Scope and THD". This application is used in a first approach to the electrical installation that is intended to be studied or monitored. It works as a digital scope with its basic functions, such as time base, vertical scale, trigger, frequency, true RMS values, DC values and peak to peak values. Another functionality of this application is the calculation of the Total Harmonic Distortion, including harmonic components until the 65th order of the signal [1]. This allows the user to have a overall perspective of the installation and also verify if the sensors are correctly installed and properly configured.

The application "PQ Events" (Power Quality Events), which main screen may be seen in Fig.4, is executed to monitor the electric installation.

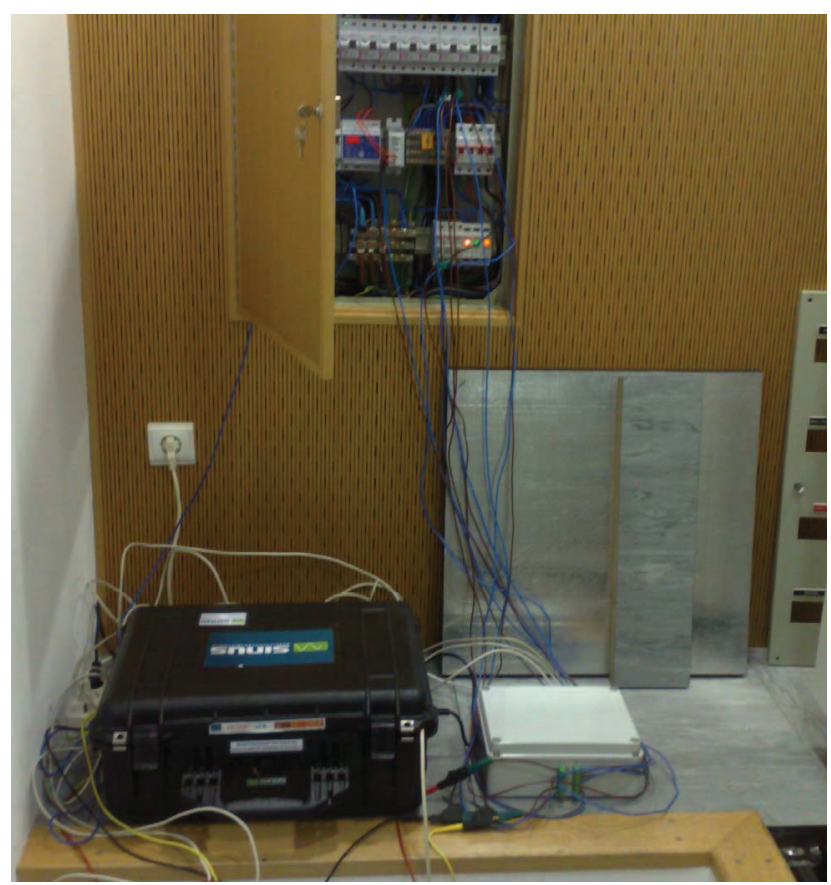

Fig. 2- Electric Power Quality Monitor installed next to an electrica switchboard.

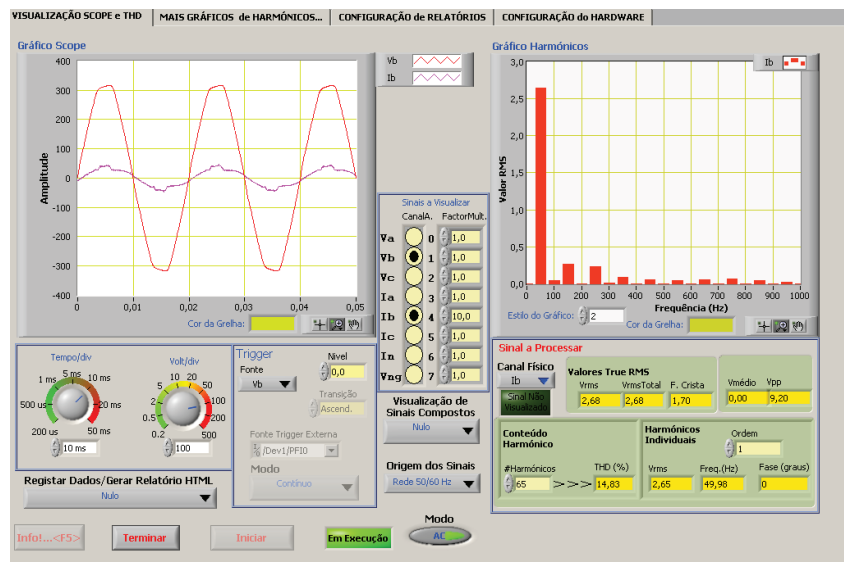

Fig. 3- Interface of the application "Scope and THD".



Fig. 4- Interface of the application "PQ Events".

This application acquires continuously the voltage and current signals and calculates the following values: True RMS values, THD, unbalances, power factor, power (apparent, active and reactive) and energy (apparent, active and reactive) [7]. These calculated values are saved in files on the hard disk of the Monitor. This application also allows detecting disturbances that cause deformations in the voltages waveforms. When it occurs, an anomaly event is saved: 12 cycles of the waveform are stored ( 6 cycles before the anomaly and 6 after the anomaly), and also are saved the date, hour, minute and second of the occurrence [1].

Furthermore, the equipment is capable of detecting voltage sags and voltage swells. When these anomalies are detected, it is saved the RMS value of the voltage in the phase where the problem occurred, and also it is saved the date and the time of the occurrence. Another functionality available in this application, is the possibility of also saving the waveform of the measured signals in a rate programmable by the user.

The periods of monitoring can be programmed from 1 minute to 30 days. At the end of the sessions, the system sends automatically e-mails to multiple recipients, informing the end of the monitoring, and giving information about the events of power quality that have occurred. 


\section{CASE StUdy RESUlts}

In order to study the data recorded by the monitoring, the Electric Power Quality Monitor is provided with an application that facilitates the analysis of the recorded data. The application "Reports", shown in Fig. 5, allows the visualization on the form of tables and graphs of the information acquired by the application "Events PQ", allowing also the automatic generation of reports in HTML or Word format. This application is an important aid in the analysis of data recorded during the monitoring, which otherwise, would be much more difficult to study [1].

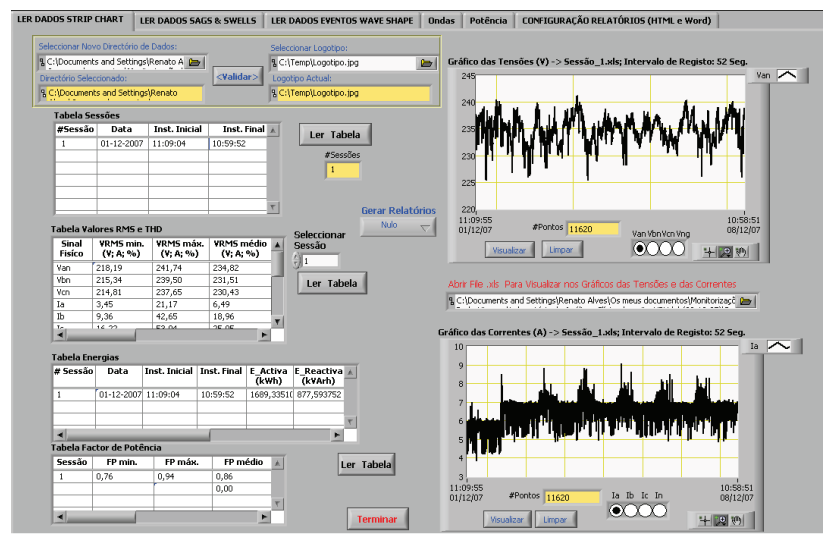

Fig. 5- Interface of the application "Reports".

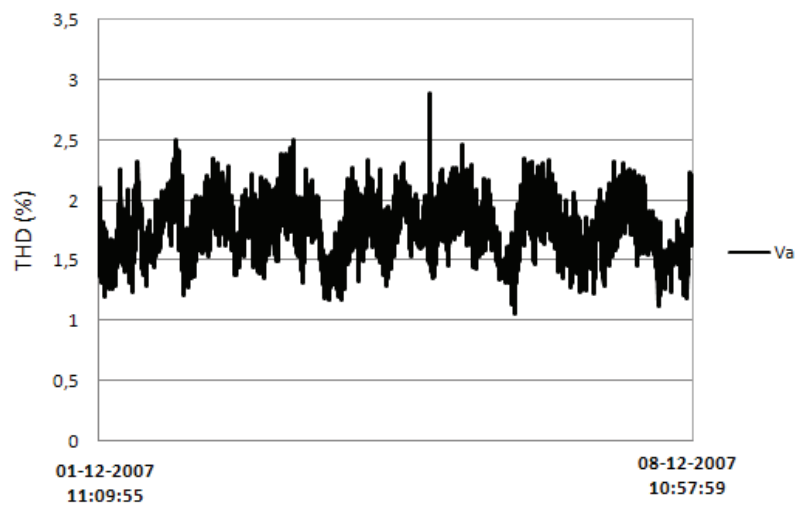

Fig. 6- Trend graph of voltage THD in phase A (registered in a clinical analysis laboratory of a hospital).

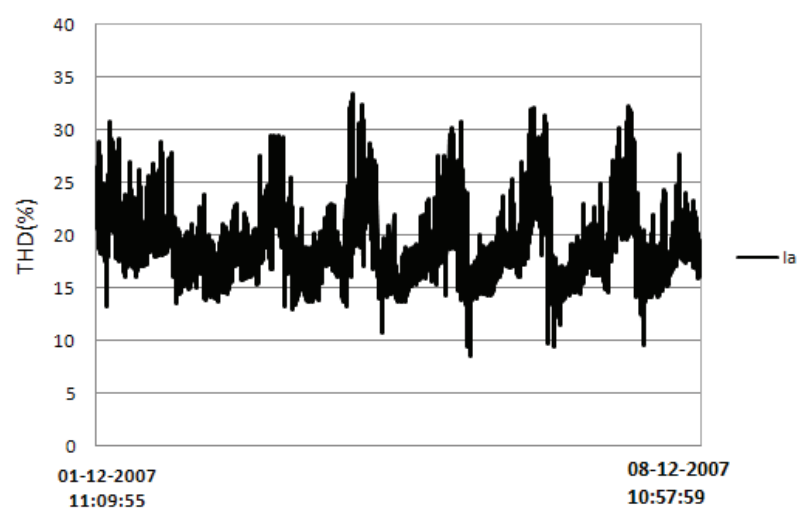

Fig. 7- Trend graph of current THD in phase A (registered in a clinical analysis laboratory of a hospital)
In Fig. 6 and in Fig. 7 are shown results produced with the help of the application "Reports". The monitoring equipment was installed in an electrical switchboard of a clinical analysis laboratory in a public hospital and it was left monitoring for the duration of a week, which allowed drawing trend graphs of consumption, THD, and other data during the time determined.

It may be seen the trend of voltage and current THD in the phase A of the electrical installation for the duration of about a week. By these graphs, it can be observed that the voltage THD has been maintained in relatively low levels and within values of European standard EN 50160 [8]. It can also be observed that during that week of monitoring, the current THD oscillates between 15 and $30 \%$.

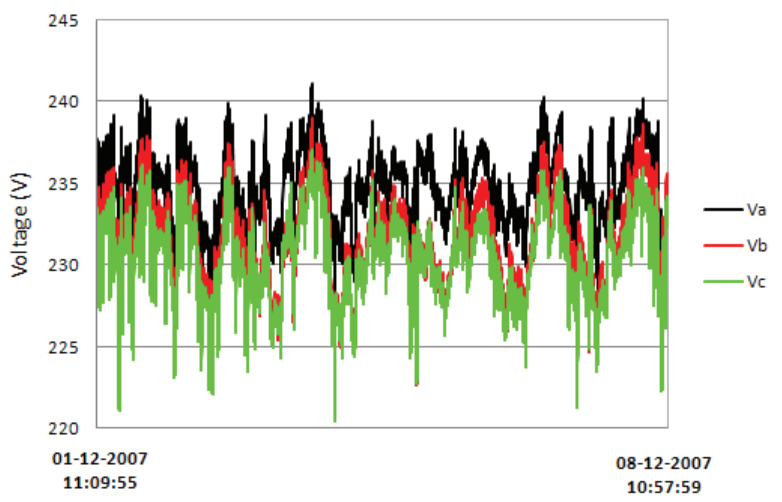

Fig. 8- Trend graph of RMS voltage in the three phases (registered in a clinical analysis laboratory of a hospital)

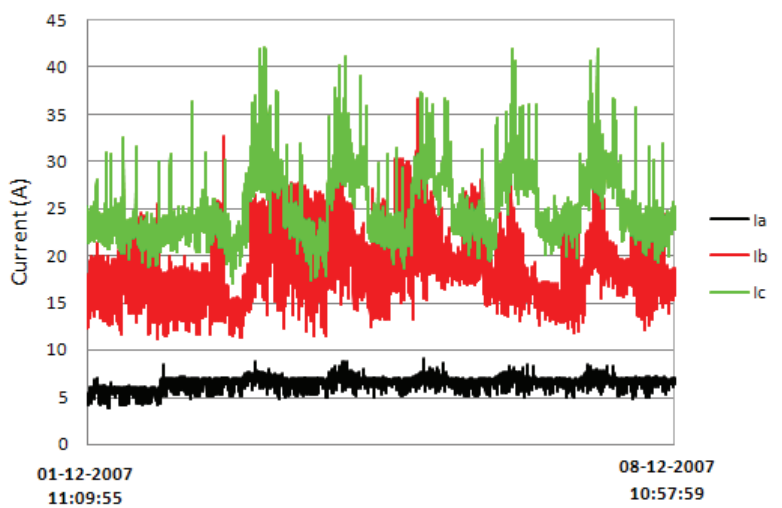

Fig. 9- Trend graph of RMS current in the three phases (registered clinical analysis laboratory of a hospital).

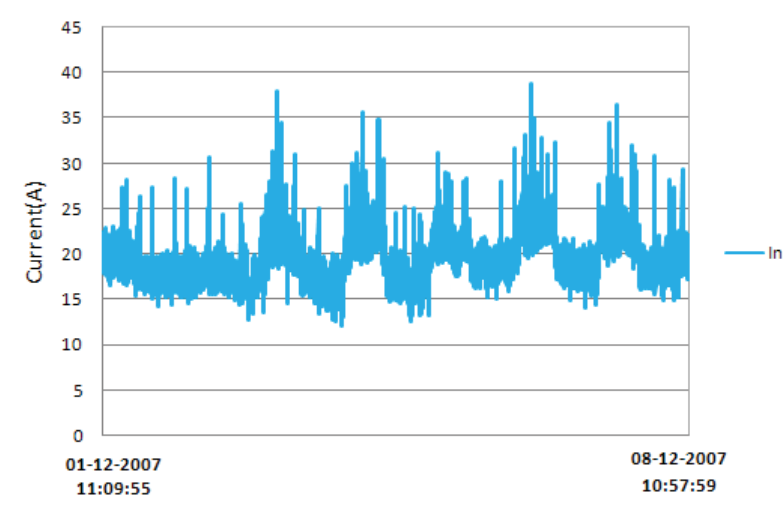

Fig. 10- Trend graph of RMS current in neutral (registered in a clinical analysis laboratory of a hospital) 
Fig. 8 shows a trend of the RMS voltage during that same week. It can be noticed by these values that the RMS voltage values oscillated between $220 \mathrm{~V}$ and $240 \mathrm{~V}$, values within the limits accepted by the European standard EN 50160. Fig. 9 and Fig. 10 show the trend of the RMS current consumption of the three phases and neutral. It can be seen that the neutral current is higher than the current in the phase A and phase B. That is due to the current unbalance of about $30 \%$ and the presence of high $3^{\text {rd }}$ order harmonic in the phase $\mathrm{C}$ current.

The application "PQ events" also allows the acquisition of other types of data. Fig. 11 and Fig.12, show the detection of similar disturbances registered in two different textile industries. This type of disturbance is detected by the Electric Power Quality Monitor as a waveform deformation. It records waveform in sliding window, allowing, if an event occurs, to record several periods before the disturbance and several periods after the disturbance. It also records the date and time and the phases where the disturbance occurred. The two different situations presented in Fig. 11 and Fig. 12 show disturbances in voltage waveform. These deformations imply a raise of the normal peak voltage which may cause damage to sensitive equipment. Especially in cases where malfunction of equipment and damage occurs, the monitoring equipment has

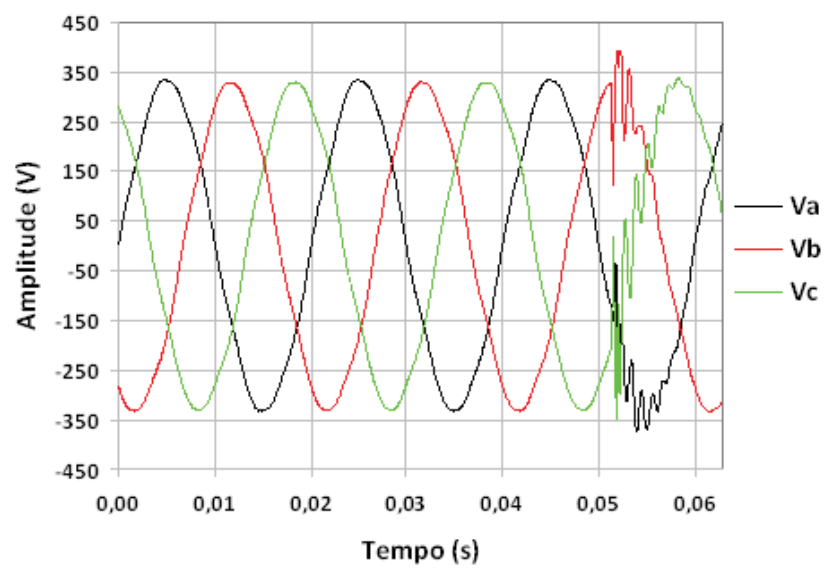

Fig. 11- Disturbances in voltage waveforms (registered in a textile industry).



Fig. 12- Disturbances in voltage waveforms (registered in a textile industry). an important role to find if the cause is related to the quality of the electric energy supplied. In both installations, the power factor is compensated through capacitors banks that are automatically adjusted by the amount of inductive loads. The disturbances presented were proved to be the result of the commutation of the banks of capacitors. Normally, these deformations in the voltage waveforms do not cause damages at the moment of the occurrence but, at medium term, these effects are felt especially in the reduction of useful life of the equipments.

In Fig. 13 and Fig. 14 is illustrated the case of an electrical installation where there is a relevant current unbalance. These results were registered in the clinical analysis laboratory aforementioned. The current unbalance occurs because the installation is constituted mainly by single phase loads and these loads are not distributed properly by the three phases. As a result, the neutral current is high. It can be verified inclusively that the current of the neutral (In) is bigger than the current in phase A $(I a)$ and phase B $(I b)$. The values of the current shown in the Fig. 13 are: $I a=6,8 \mathrm{~A}, I b=20,5 \mathrm{~A}, I c=$ $29,9 \mathrm{~A}$ and $\mathrm{In}=21,1 \mathrm{~A}$. This situation is reflected in a current unbalance of $34,3 \%$. This poor load distribution may cause the

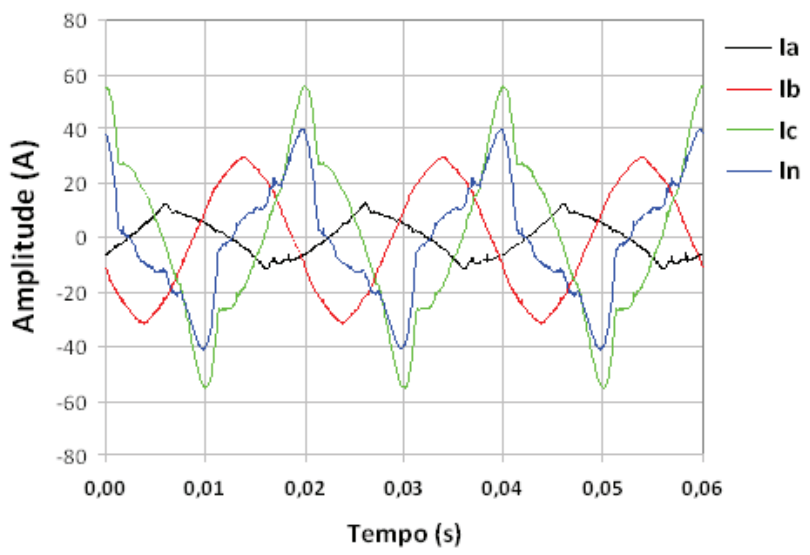

Fig. 13- Current waveforms (registered in a clinical analysis laboratory of a hospital).

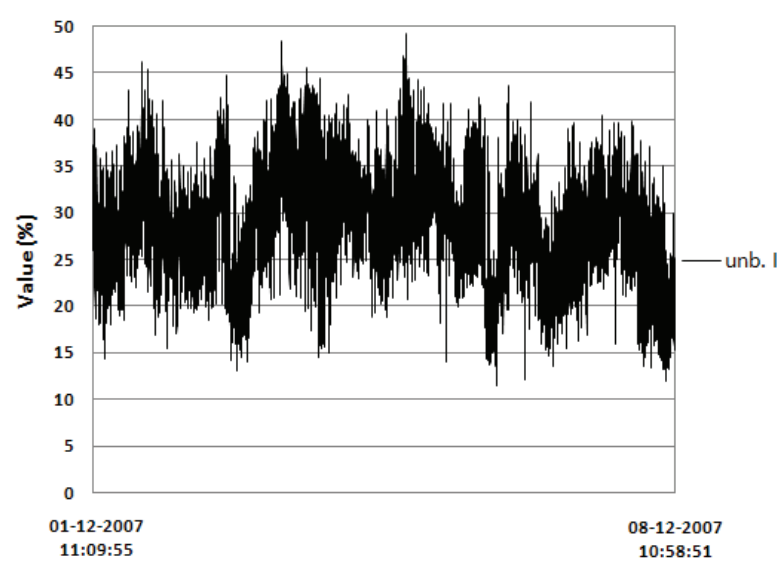

Fig. 14- Trend Graph of the percent current unbalance (registered in a clinical analvsis laboratory of a hospital). 
system to be overloaded in a particular phase and have another phase miss used. Also, the neutral current becomes higher than if the system was unbalanced and power losses increase. An electric energy monitoring may be useful to help correct this problem either by load distribution, either be use of active filters [9] [11] if there is a difficulty to change the loads connection to the power grid.

Fig. 14 shows a trend graph of the unbalance percent during a week. This graph gives an idea of the possibilities to correct the problem informing the times at which the unbalances happen making it easier to chose the loads to change phase.

The existence of harmonics of order multiple of 3 in the current makes it appear current in the neutral, even with balanced load distribution by the three phases. In many installations, due to these situations, the neutral current is much higher than the phase currents. This phenomenon makes it mandatory to use a neutral wire with a section much larger than it would be necessary if the loads didn't cause the neutral current to be that high. Fig. 5 shows the current waveforms of the three phases and neutral of an electric power monitoring in an electrical installation of computer rooms at the University of Minho. The RMS values of the current are: $I a=22,8 \mathrm{~A}$, $I b=21,5 \mathrm{~A}, I c=15,2 \mathrm{~A}$ e $I n=20,4 \mathrm{~A}$. As it can be seen, the RMS value of current in neutral $(I n)$ is high and even higher than the current in phase A $(I a)$. This current of neutral is

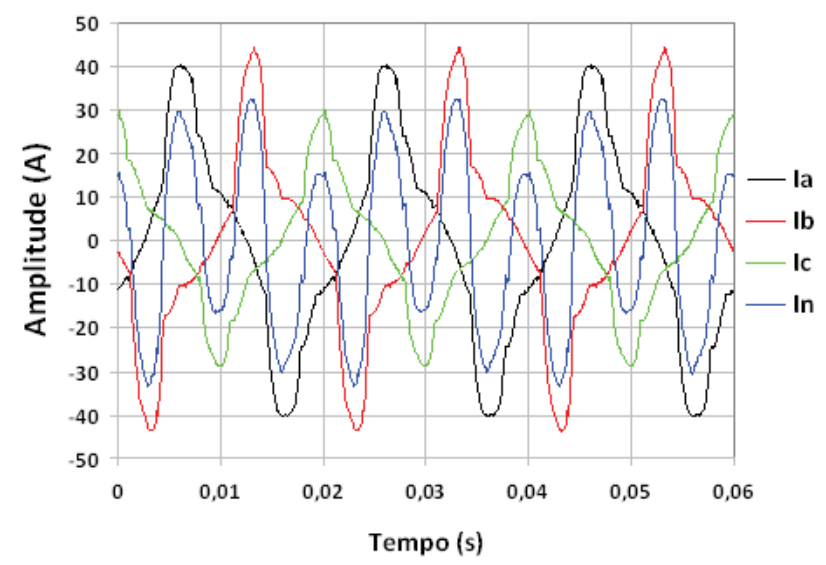

Fig. 15- Current waveforms registered in a University of Minho.

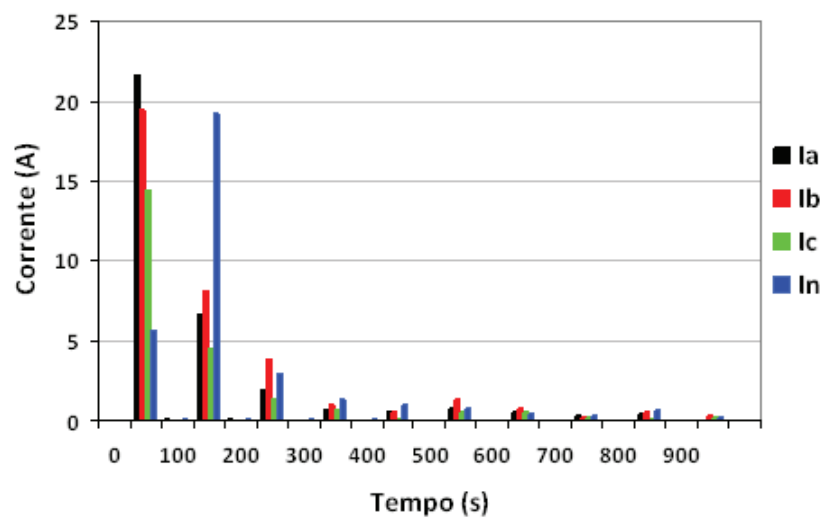

Fig.16- Harmonic graph of the waveforms presented in Fig. 15. originated by the harmonic of order 3 in the current of the phases. The 3th harmonic of the current of the neutral is greater than 1th harmonic as shown in the harmonic graph of the Fig. 16. The high neutral current caused by harmonic distortion may be mitigated by the use of passive filters or active filters [11] if this situation is known to cause any disturbance in the electric system.

It is usual to have a considerable amount of harmonic distortion in current because of non linear loads. Fig. 17 presents waveforms of voltage and current measured in a textile industry. It can be observed that the voltage has a high

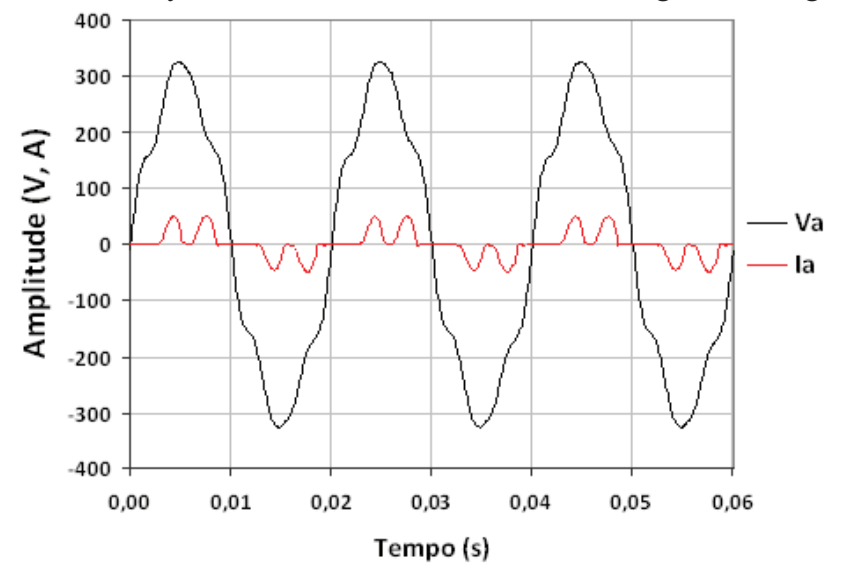

Fig. 17- Waveforms of the voltages and currents in phase A (registered in a textile industry).

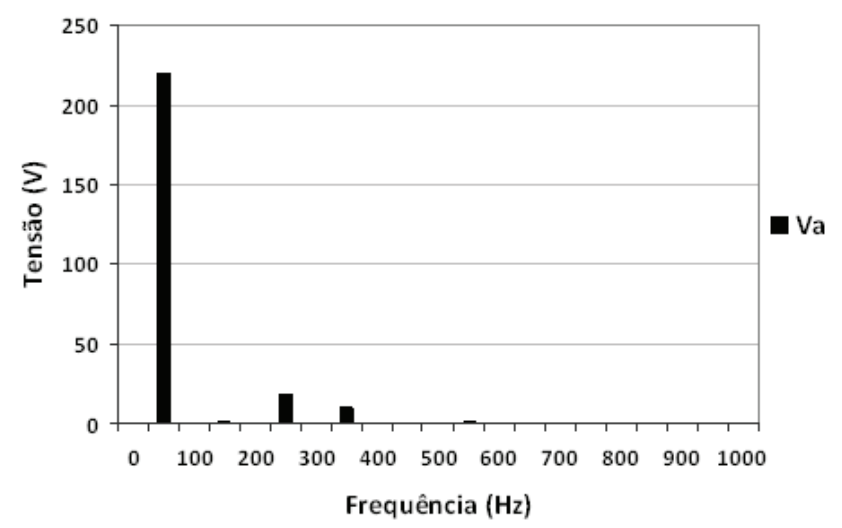

Fig. 18- Harmonics graph of the voltage waveform presented in Fig.17.

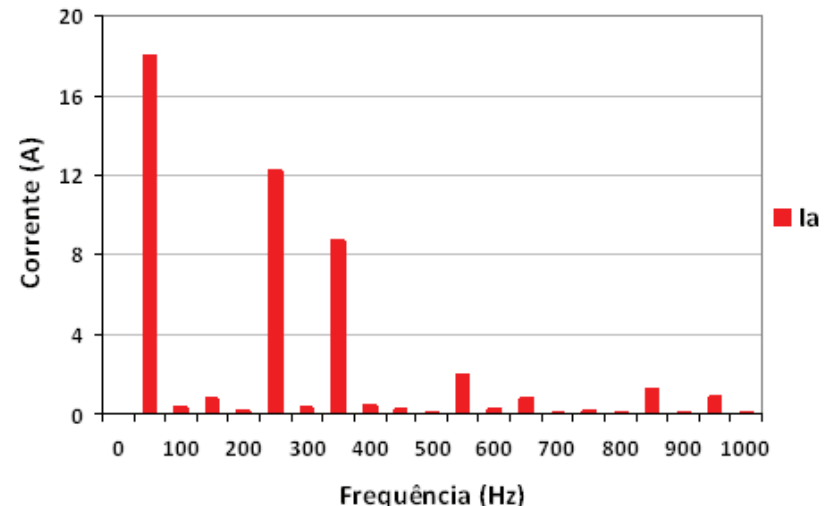

Fig. 19- Harmonics graph of the current waveform presented in Fig. 17. 
harmonic content. In this case the THD measured was of $10 \%$. This value of harmonic content in voltage exceeds the stipulated by the norm EN 50160 that it is of 8\% [8].

In the case presented the loads present a high value of $5^{\text {th }}$ harmonic consumption, as it can be seen in Fig. 18. The equipment that consumes the current as presented in Fig. 17 is a machine with several Variable Frequency Drives (VFD) feeding induction motors. These equipments are known to have at their input a three-phase rectifier with smoothing capacitors at which cause current with high $5^{\text {th }}$ and $7^{\text {th }}$ harmonics.

\section{CONCLUSIONS}

This paper presented different Electric Power Monitoring results in which were identified different kinds of undesired situations. In one of the cases, it was found that the neutral current was much higher than one of the phase currents. This phenomenon is caused by poor load distribution, causing unbalance, and by loads that produce 3rd order harmonics in currents, that add up in the neutral wire. With these effects, the neutral wire may have to be replaced with larger section wires in old electrical installations, or carefully sized in new ones.

In another case, it was identified disturbances in the voltage waveform caused by the automatic commutation of capacitor banks. This may cause the deterioration or malfunction of sensitive equipment.

Another undesirable situation observed, was the presence of high value of THD in current waveform caused by the presence of non linear loads. Also, an effect of having many non linear loads is the increase of losses in power lines and the increase of THD in voltage waveform, in some cases higher than limits imposed by standards.

The Electric Power Quality Monitor may be used to have further knowledge about the electrical installation characteristics. The information acquired may be used to implement changes in the electrical installation improving its efficiency. Also, the Monitor can be used to follow the energy spent, having an idea of the loads that more contribute for the electricity costs.

The Electric Power Quality Monitor developed in the Energy and Power Electronics laboratory of the University of Minho has the capability of performing analysis to the electrical installations of industries and services. Furthermore, it is a low cost equipment, with a user friendly interface, making it a tool easily applicable to most electrical installations.

\section{ACKNOWLEDGMENT}

This work supported by FCT (Fundação Para a Ciência e a Tecnolgia), project funding POCTI/ESE41170/2001 and POCTI/ESE/48242/2002. The authors are also grateful to PRIME (Programa de Incentivos à Modernização da Economia) for funding the Project SINUS.

\section{REFERENCES}

[1] Renato Alves ; Sistema de Monitorização de Consumos Energéticos e da Qualidade da Energia Eléctrica; Tese de Mestrado Integrado; Universidade do Minho; 2008.

[2] José Batista; Sistema de Monitorização da Qualidade da Energia Eléctrica Baseada em PC; Tese de Mestrado; Universidade do Minho; 2004.

[3] J. Batista, J. S. Martins, J. L. Afonso, "Low-Cost Power Quality Monitor Based on a PC", ISIE'2003 - IEEE International Symposium on Industrial Electronics, R.J., Brasil, Jun 2003; https://repositorium.sdum.u minho.pt/bitstream/1822/1777/1/8CLEEE_JB.pdf

[4] J. Batista, J. S. Martins, J. L. Afonso, Sistema de Monitorização da Qualidade da Energia Eléctrica Baseado em PC; $8^{\circ}$ Congresso LusoEspanhol de Engenharia Electrotécnica; Vilamoura, Algarve, Portugal; 35 Julho de 2003; https://repositorium.sdum.uminho.pt/bitstream/1822/17 77/1/8CLEEE_JB.pdf

[5] J. Batista, J. S. Martins, J. L. Afonso, "Low-Cost Digital System for Power Quality Monitoring”, ICREPQ’03 - International Conference on Renewable Energies and Power Quality, Vigo, Espanha, Abril de 2003. https://repositorium.sdum.uminho.pt/bitstream/1822/1771/1/ICREPQ03_JB.pdf

[6] José C. C. Costa, Ricardo L. Pregitzer, Tiago N. Sousa, José Batista, João L. Afonso, "A Case of Power Quality Assessment Using a Developed Power Quality Monitor", CEE'05 - IEEE 1st International Conference on Electrical Engineering, Coimbra, Portugal, ISBN: 972-99064-32, 10-12 Out. 2005.

https://repositorium.sdum.uminho.pt/bitstream/1822/4138/1/CEE05_PQM.pdf

[7] IEEE, "Definitions for the Measurement of Electric Power Quantities Under Sinusoidal, Nonsinusoidal, Balanced, or Unbalanced Conditions", IEEE Trial-Use Standard, IEEE Std 1459-2000, 2000

[8] CENELEC, Instituto Português da Qualidade, "Características da tensão fornecida pelas redes de distribuição pública de energia eléctrica", versão portuguesa da norma europeia EN 50160, 2a edição, Dezembro 2001.

[9] João L. Afonso, R. Pregitzer, J. G. Pinto, Luís Monteiro, Pedro Neves, R. Alves, D. Gonçalves, José Cunha, José Batista, Júlio S. Martins, M. J. S. Freitas, Eduardo Pinto, Renato Morgado, "SINUS - Tecnologia para Monitorização da Qualidade de Energia, Compensação Dinâmica de Harmónicos, Factor de Potência e Desequilíbrios e para Interface de Fontes Renováveis", Proceedings of XCLEEE - 10th Portuguese-Spanish Congress in Electrical Engineering, Funchal, Portugal 5th-7th July 2007.

[10] Ricardo Pregitzer, J. C. Costa, Júlio S. Martins, and João L. Afonso, "Simulation and Implementation Results of a 3 Phase 4 Wire Shunt Active Power Filter", ICHQP'2006 - International Conference on Harmonics and Quality of Power, 1-5 Oct. 2006, Cascais, Portugal.

[11] M.Izhar, C.M.Hadzer, Syafrudin.M, S.Taib and S.Idris, Performance for Passive and Active Power Filter in Reducing Harmonics in the Distribution System, National Power \& Energy Conference PECon 2004 Proceedings, Kuala Lumpur, Malaysia, 2004. 